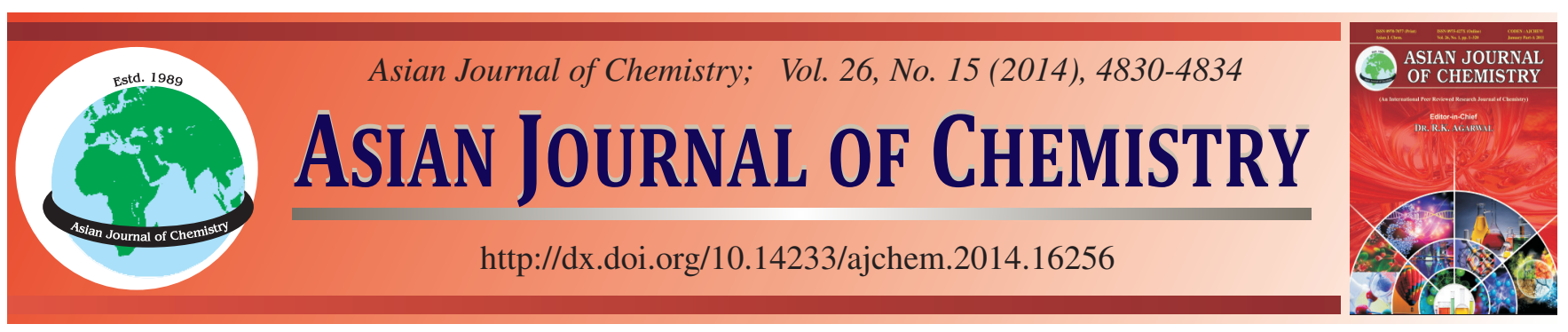

\title{
Optimization of Ultrasonic-Assisted Extraction of Flavonoids from Fenugreek Using Response Surface Methodology and High-Performance Liquid Chromatography- Diode Array Detector Coupled with Mass Spectrometry Analysis
}

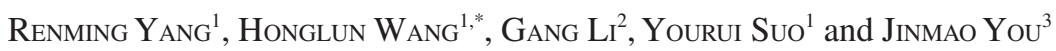

${ }^{1}$ Key Laboratory of Tibetan Medicine Research, Northwest Institute of Plateau Biology, Chinese Academy of Sciences, Xining 810001, P.R. China

${ }^{2}$ Life School of Yantai University, Yantai 264005, P.R. China

${ }^{3}$ College of Chemistry Science, Qufu Normal University, Qufu 273165, Shandong Province, P.R. China

*Corresponding author: Tel/Fax: +86 971 6143857; E-mail: hlwang@nwipb.cas.cn

Received: 30 August 2013;

Accepted: 12 December 2013;

Published online: 16 July 2014;

AJC-15581

In this study, a central composite design based on response surface methodology was used to optimize ultrasonic-assistant extraction of flavonoids from Trigonella foenum-graecum L. The optimal conditions to obtain the highest yield of total flavonoids were as follows: ultrasonic time of $80 \mathrm{~min}$, temperature of $48^{\circ} \mathrm{C}$ and liquid to solid ratio of $20 \mathrm{~g} / \mathrm{mL}$, where $1.03 \%$ yield was predicted. After extraction process optimization, a method for the analysis of flavonoids in Trigonella foenum-graecum L. by HPLC-DAD-MS was developed. The LOD and LOQ of these 4 compounds range from 50.94 to $70.31 \mathrm{ng} / \mathrm{mL}$ and 179.63 to $208.85 \mathrm{ng} / \mathrm{mL}$, respectively. The established HPLC-DAD-MS method was proven to be useful for the quantitative and qualitative analysis of flavonoid constituents in fenugreek seed. This is the first report on preparation, identification and determination of flavonoids in fenugreek seed by different method and which would provide a basis for medicinal and edible use of fenugreek.

Keywords: Fenugreek, Flavonoids, Response surface methodology, Ultrasound-assisted extraction, Quantitative analysis.

\section{INTRODUCTION}

Fenugreek (Trigonella foenum-graecum L.) is an annual plant of Trigonella Linn widely used in Asia, Africa and Mediterranean countries for its nutritional and medicinal value. Saponins ${ }^{1}$, flavonoids ${ }^{2,3}$, galactomannans ${ }^{4}$, trigonelline and 4-hydroxyisoleucine ${ }^{5}$ were isolated from the seeds of fenugreek in previous phytochemical research. The seeds of this plant are used in folk medicine due to their hypoglycemic ${ }^{6}$, hypolipidemic $^{7}$ and other effects. Fenugreek seeds are a good source of flavonoids, including flavones and flavones-c-glycosides ${ }^{2}$, flavononl and flavononl-c-glycosides ${ }^{8}$, isoflavones and isoflavones-c-glycoside ${ }^{3}$ and flavanones ${ }^{9}$. Fenugreek seed flavonoids has some useful effects, such as hypoglycemic effects ${ }^{10}$, promoting 2BS cell proliferation ${ }^{3}$ and antioxidant properties ${ }^{11}$.

Flavonoid is produced by conventional extraction method such as heating, boiling or refluxing. However, the disadvantages of these methods are time-consuming and the loss of flavonoids. In recent years, various new techniques such as ultrasonic-assisted extraction ${ }^{12}$, microwave-assisted extraction ${ }^{13}$ and supercritical carbon dioxide extraction ${ }^{14}$ have been established for the extraction of total flavonoids from natural plants. Among them, ultrasonic-assisted extraction has attracted much attention due to its relatively low cost and high extraction efficiency compared with conventional extraction techniques.

The response surface methodology (RSM) has been demonstrated to be a useful tool to determine the factors effects and their interactions and allowing process optimization to be conducted effectively ${ }^{12}$. Response surface methodology with central composite design (CCD) or Box-Behnken design (BBD) was used to optimize the extraction conditions. Recently, RSM was applied to optimize the extraction of flavonoids from Prunella vulgaris L. ${ }^{15}$, Euterpe oleracea ${ }^{16}$, etc.

Investigations about the potential of fenugreek as a nutritional source of flavonoids or possibly even as a functional food or medicine are also ongoing. In the present study, one ultrasonic-assisted extraction was used for the flavonoidsenriched extract from Trigonella foenum-graecum L. were investigated and the operational parameters were optimized using RSM with CCD.

\section{EXPERIMENTAL}

Trigonella foenum-graecum L. (fenugreek) seeds were collected during autumn at 2009 from Datong in Qinghai province and were dried at $60{ }^{\circ} \mathrm{C}$ for $24 \mathrm{~h}$ in an oven and then 
comminuted into pieces by a crusher and flour was passed through a 40 mesh $(0.63 \mathrm{~mm})$ sieve and stored at $4{ }^{\circ} \mathrm{C}$ in darkness before analysis. Orientin and vitexin were purchased from Chengdu Must Bio-Technology Co., Ltd. Isovitexin, rutin and isoorientin were obtained from Shanghai Winherb Medical S\&T Development Co., Ltd. Chromatographic pure methanol was purchased from Shandong Yuwang Industrial Co., Ltd.

Ultrasonic-assisted extraction (UAE): The powdered fenugreek seed was accurately weighed and soaked with $70 \%$ ethanol and then placed in ultrasonic bath and sonicated at $80 \mathrm{~W}, 40 \mathrm{KHz}$ for certain temperature and certain time and certain solid to liquid ratio based on preliminary trails (no reported here). After extraction, the extract solution was collected and dissolved by $70 \%$ ethanol and added to $100 \mathrm{~mL}$ to compensate for the loss of weight. Then the solution was stored in $4{ }^{\circ} \mathrm{C}$ in darkness until further determination of total flavonoids and HPLC/MS analysis.

Experimental design and data analysis: Response surface methodology combined with CCD was applied to optimize the extraction temperature (X1), time(X2) and solid to liquid ratio (X3) for ultrasonic-assisted extraction of flavonoids from fenugreek seed. In the CCD test, the actual and coded levels of the independent variables used in the experimental design are shown in Table-1. The coded variables equation follows the references ${ }^{9,16}$ and showed in formula 1:

$$
Y=\beta_{0}+\sum_{j=1}^{k} \beta_{j} X_{j}+\sum_{j=1}^{k} \beta_{j j} X_{j}^{2}+\sum \sum_{i<j} \beta_{i j} X_{i} X_{j}(k=3)
$$

where $\mathrm{k}$ is the numbers of variables, $\beta_{0}$ is the constant term, $\beta_{\mathrm{i}}, \beta_{\mathrm{ii}}$ and $\beta_{\mathrm{ij}}$ represents the coefficient of the first order terms, quadratic terms and interaction terms, respectively, while $X_{i}$ and $\mathrm{X}_{\mathrm{j}}$ are the independent coded variables.

During the entire experimental process, the extraction temperature varying from 45 to $75^{\circ} \mathrm{C}$, time varying from 60 to $120 \mathrm{~min}$ and liquid to solid ratio varies from 10:1 to 20:1. A response surface analysis procedure (Design-Expert 7.1.3 Trial, State-Ease, Inc., Minneapolis MN, USA) was used for calculations and modeling of optimal conditions for ultrasonic-assisted extraction of flavonoids from fenugreek seed. Values of $\mathrm{P}<$ 0.01 were regarded as significant.

Heating reflux extraction of flavonoids (HRE): Ground dried fenugreek seeds were extracted by $60 \mathrm{~mL} 70 \%$ ethanol solution at $80{ }^{\circ} \mathrm{C}$ for $120 \mathrm{~min}$ based on former research. After extraction, the extract solution was collected and dissolved by $70 \%$ ethanol and added to $100 \mathrm{~mL}$ to compensate for the loss of weight. The solution was stored in $4{ }^{\circ} \mathrm{C}$ until further determination of total flavonoids and HPLC-DAD-MS analysis.

Determination of total flavonoids: The total flavonoids content was measured spectrophotometrically using a method described by Kong et al. $^{17}$. A standard calibration curve of rutin $(\mathrm{y}=10.214 \mathrm{x}+0.0045, \mathrm{r}=0.9994$, where $\mathrm{y}$ is absorbance value of fenugreek sample, $\mathrm{x}$ is sample concentration) ranged $0.00-0.05 \mathrm{mg} / \mathrm{mL}$ was plotted to calculate the results. The flavonoid content was expressed in terms of fresh weight as the $\mathrm{mg}$ rutin equivalent per $100 \mathrm{mg}$ of dried fenugreek seed.

HPLC-DAD and LC-MS/MS analysis: Experiments were performed using Agilent HP 1100 Series HPLC (Agilent, USA). The LC system consisted of an online vacuum degasser, a quaternary pump, an auto-sampler, a thermostated column compartment and diode array detector. The mass spectrometer 1100 Series LC-MSD Trap-SL (ion trap) from Bruker Daltonik was equipped with an electrospray ionization (ESI) source.

HPLC-DAD analysis: The chromatographic separation of flavonoids was achieved by using a reversed-phase Hypersil BDS C18 column $(250 \times 4.6 \mathrm{~mm}, 5 \mu \mathrm{m}$, Agela Technologies Inc, Wilmington, USA) in conjunction with a gradient elution. The mobile phase consisted of water (solvent A) and pure methanol (solvent B), The initial composition of solvent B was $20 \%$ and was linearly increased to $30 \%$ at $30 \mathrm{~min}$, to $40 \%$ at $33 \mathrm{~min}$, to $50 \%$ at $50 \mathrm{~min}$. An aliquot of $10 \mu \mathrm{L}$ solution was injected automatically. The chromatogram was monitored at $340 \mathrm{~nm}$ and UV spectra of individual peaks were recorded in the range of 200-400 $\mathrm{nm}$. The flow rate was $1 \mathrm{~mL} / \mathrm{min}$ and temperature was $30^{\circ} \mathrm{C}$. Chromatographic peaks were identified by spiked the working standard with each individual flavonoids in turn.

HPLC-DAD-ESI-MS analysis: The ESI source was operated in positive-ion mode with a full scan mass range from $\mathrm{m} / \mathrm{z} 150$ to 1200 . The chromatographic separation condition was the same with the HPLC/DAD analysis mentioned above. The MS conditions were listed as follow: positive ion mode; gas $\left(\mathrm{N}_{2}\right)$ temperature, $350{ }^{\circ} \mathrm{C}$; flow rate, $9 \mathrm{~L} / \mathrm{min}$; nebulizer pressure, 35 psi; capillary voltage, $3.5 \mathrm{kV}$; cone voltage, $40 \mathrm{~V}$; corona current (nA), 4000 (pos).

Quantitative analysis of individual flavonoid, limit of detection (LOD), limit of quantity (LOQ) and recovery: Stock solutions of orientin $(0.22 \mathrm{mg} / \mathrm{mL})$, isoorientin $(0.23$ $\mathrm{mg} / \mathrm{mL})$, vitexin $(0.23 \mathrm{mg} / \mathrm{mL})$, isovitexin $(0.21 \mathrm{mg} / \mathrm{mL})$ were prepared in methanol. Then, a set of mixed standard solutions were prepared by appropriate dilution of the stock solution with methanol. All solutions were stored at $4{ }^{\circ} \mathrm{C}$ in darkness before analysis. The calibration curve of flavonoid reference standard was prepared by plotting mass concentration(x, $\mathrm{mg} / \mathrm{mL}$ ) against its peak area (y) at $\lambda=340 \mathrm{~nm}$. The fenugreek seed flavonoids samples got by ultrasonic-assisted extraction (at the optimal condition), conventional heating reflux extraction were determined in triplicate.

The detection limits were estimated experimentally by injecting standard solutions of each flavonoids diluted in methanol until the signal-to-noise ratio for the standards reached a 3:1 ratio for LOD and a 10:1 for LOQ. Recovery experiments were performed to evaluate the accuracy of the methods. Three different concentrations of orientin, isoorientin, vitexin and isovitexin were added to known amounts, which where compared with fenugreek seed ultrasonic-assisted extraction without standards. The spiked samples were analyzed in triplicate by the established HPLC method. Accuracy was expressed as the percentage deviation between the amount of standard found by HPLC analysis and the amount added at the known concentrations.

\section{RESULTS AND DISCUSSION}

The RSM with CCD was used to evaluate the extraction parameters (X1, X2, X3) and optimize the experimental conditions in the ultrasonic-assisted extraction process. The flavonoids yield data under different extraction conditions were presented in Table-1. 


\begin{tabular}{|c|c|c|c|c|}
\hline \multicolumn{5}{|c|}{$\begin{array}{l}\text { TABLE-1 } \\
\text { EXPERIMENTAL SCHEME AND RESULTS OBTAINED FROM } \\
\text { RSM FOR THE FLAVONOIDS YIELD }(\overline{\mathrm{x}} \pm \mathrm{s}, \mathrm{n}=3)\end{array}$} \\
\hline No. & $\begin{array}{c}\text { Time } \\
(\mathrm{X} 1, \mathrm{~min})\end{array}$ & $\begin{array}{c}\text { Temperature } \\
\left(\mathrm{X} 2,{ }^{\circ} \mathrm{C}\right)\end{array}$ & $\begin{array}{c}\text { Liquid to } \\
\text { solid ratio } \\
\text { (X3,g/mL) }\end{array}$ & $\begin{array}{c}\text { Flavonoids } \\
\text { yield (\%) }\end{array}$ \\
\hline 1 & $1(80)$ & $1(50)$ & $1(20)$ & $1.03 \pm 0.04$ \\
\hline 2 & 1 & 1 & $-1(10)$ & $0.96 \pm 0.02$ \\
\hline 3 & 1 & $-1(30)$ & 1 & $0.99 \pm 0.04$ \\
\hline 4 & 1 & -1 & -1 & $0.88 \pm 0.01$ \\
\hline 5 & $-1(40)$ & 1 & 1 & $0.88 \pm 0.03$ \\
\hline 6 & -1 & 1 & -1 & $0.76 \pm 0.02$ \\
\hline 7 & -1 & -1 & 1 & $0.81 \pm 0.05$ \\
\hline 8 & -1 & -1 & -1 & $0.76 \pm 0.04$ \\
\hline 9 & $-1.682(26.4)$ & 0 & $0(15)$ & $0.80 \pm 0.06$ \\
\hline 10 & $1.682(93.6)$ & 0 & 0 & $1.02 \pm 0.02$ \\
\hline 11 & $0(60)$ & $1.682(56.8)$ & 0 & $0.96 \pm 0.01$ \\
\hline 12 & 0 & $-1.682(23.2)$ & 0 & $0.80 \pm 0.03$ \\
\hline 13 & 0 & $0(40)$ & $1.682(23.4)$ & $0.97 \pm 0.03$ \\
\hline 14 & 0 & 0 & $-1.682(6.6)$ & $0.85 \pm 0.04$ \\
\hline 15 & 0 & 0 & 0 & $0.92 \pm 0.02$ \\
\hline 16 & 0 & 0 & 0 & $0.91 \pm 0.04$ \\
\hline 17 & 0 & 0 & 0 & $0.93 \pm 0.02$ \\
\hline 18 & 0 & 0 & 0 & $0.90 \pm 0.03$ \\
\hline 19 & 0 & 0 & 0 & $0.91 \pm 0.01$ \\
\hline 20 & 0 & 0 & 0 & $0.91 \pm 0.02$ \\
\hline HRE & 120 & 80 & 40 & $0.89 \pm 0.01$ \\
\hline
\end{tabular}

As showed in Table-1, the fenugreek seed flavonoids yield by UAE was from 0.76 to $1.03 \%$, the maximum yield of $1.03 \%$ was obtained at condition of $80 \mathrm{~min}, 50{ }^{\circ} \mathrm{C}$ and 20 $\mathrm{g} / \mathrm{mL}$ and the maximum yield of HRE was $0.90 \%$ at $2 \mathrm{~h}, 80^{\circ} \mathrm{C}$ and $20 \mathrm{~g} / \mathrm{mL}$.

Regression modeling of ultrasonic-assisted extraction: According to RSM design, the flavonoids yield obtained from all the CCD experiments is listed in Table-1. Experimental results were analyzed using RSM. The second order polynomial equation that fitted the coded variables follows the previous studies ${ }^{18}$. The developed regression model for the relationship between flavonoids yield (Y) and the uncoded values of independent variables of $\mathrm{X} 1, \mathrm{X} 2$ and $\mathrm{X} 3$ and their interaction is shown in the following equation:

$$
\begin{gathered}
Y=0.1529+3.0423 \times 10^{-3} \mathrm{X}_{1}+0.0191 \mathrm{X}_{2}+7.3127 \\
\times 10^{-3} \mathrm{X}_{3}-3.7500 \times 10^{-5} \mathrm{X}_{1} \mathrm{X}_{2}+1.5000 \times 10^{-4} \mathrm{X}_{1} \mathrm{X}_{3} \\
-2.0000 \times 10^{-4} \mathrm{X}_{2} \mathrm{X}_{3}-33.8385 \times 10^{-6} \mathrm{X}_{1}^{2}-1.2142 \\
\times 10^{-4} \mathrm{X}_{2}^{2}-6.1416 \times 10^{-5} \mathrm{X}_{3}^{2}
\end{gathered}
$$

The analysis of variance for the response surface model is given in Table- 2 and indicated that time and temperature were significant at the level of $\mathrm{P}<0.01$. The results showed the model predicted for the flavonoids yield was adequate as indicated by error analysis that showed non-significant lackof-fit $(\mathrm{P}>0.05)$. The regression model for the flavonoids yield was highly significant $(\mathrm{P}<0.01)$. The value of $\mathrm{R}^{2}(0.9905)$ revealed that the experimental data were in good agreement with the predicted values of fenugreek seed flavonoids yield. F-value for the lack of fit was also insignificant $(\mathrm{P}>0.05)$, meaning that this model was sufficiently accurate for predicting the relevant responses. Coefficient of variation (C.V. \%) was $1.11 \%$ indicated that the model has a better precision and reliability.

\begin{tabular}{|c|c|c|c|c|c|}
\hline Variables & $\begin{array}{l}\text { Degree of } \\
\text { freedom }\end{array}$ & $\begin{array}{l}\text { Sum of } \\
\text { Squares }\end{array}$ & $\begin{array}{c}\text { Mean } \\
\text { squares }\end{array}$ & F-value & P-value \\
\hline $\begin{array}{c}\text { Quadratic } \\
\text { Model }\end{array}$ & 9 & 0.100 & 0.012 & 115.39 & $<0.0001$ \\
\hline X1 & 1 & 0.061 & 0.050 & 606.55 & $<0.0001$ \\
\hline $\mathrm{X} 2$ & 1 & 0.024 & 0.013 & 237.22 & $<0.0001$ \\
\hline X3 & 1 & 0.014 & 0.010 & 142.98 & $<0.0001$ \\
\hline $\mathrm{X} 1 \mathrm{X} 2$ & 1 & $4.500 \times 10^{-4}$ & $4.500 \times 10^{-4}$ & 4.50 & 0.0599 \\
\hline X1X3 & 1 & $1.800 \times 10^{-4}$ & $1.800 \times 10^{-4}$ & 18.01 & 0.0017 \\
\hline $\mathrm{X} 2 \mathrm{X} 3$ & 1 & $8.000 \times 10^{-4}$ & $8.000 \times 10^{-4}$ & 8.00 & 0.5728 \\
\hline $\mathrm{X} 1 \mathrm{X} 1$ & 1 & $3.397 \times 10^{-5}$ & $3.397 \times 10^{-5}$ & 0.34 & 0.0010 \\
\hline $\mathrm{X} 2 \mathrm{X} 2$ & 1 & $2.215 \times 10^{-3}$ & $2.215 \times 10^{-3}$ & 21.25 & $<0.0001$ \\
\hline X3X3 & 1 & $3.397 \times 10^{-5}$ & $3.397 \times 10^{-5}$ & 0.34 & 0.5728 \\
\hline Lack of fit & $4.663 \times 10^{-4}$ & 5 & $4.663 \times 10^{-4}$ & 0.87 & 0.5568 \\
\hline Pure error & $5.333 \times 10^{-4}$ & 5 & $5.333 \times 10^{-4}$ & & \\
\hline Total error & 0.10 & 19 & & & \\
\hline
\end{tabular}

TABLE-2

ANOVA ANALYSIS OF PREDICATED SECOND-ORDER POLYNOMIAL MODEL FOR THE RESPONSE VARIABLE

Response surface analysis: Multiple regression coefficients, obtained by employing a least squares technique to predict a second-order polynomial model for the flavonoids yield, are summarized in Table-2. As shown in Table-2, all the three factors had big effects on the flavonoids yield and interaction of time and liquid to solid ratio had the most significant effect than other combination of extraction parameters. From Table-2, it is found that quadratic terms of time and temperature were highly significant $(\mathrm{P}<0.01)$. There was significant interaction $(\mathrm{P}<0.05)$ between $\mathrm{X} 1 \mathrm{X} 3$ for the flavonoids yield. There was not significant interaction $(\mathrm{P}>0.05)$ of X1X2 and X2X3 within the experimental range. 3D shaded surfaces of second-order polynomial model were used to predict the interactive effects of operational parameters for the ultrasonic-assisted extraction seed flavonoids (Figs. 1-3).

Fig. 1 is the three-dimensional response surface showing the effect of time and temperature on the flavonoids yield. The extraction temperature is one of the main parameters that to affect the extraction yield. When at a given temperature, the flavonoids yield increased with the rise of time. Temperature had a positive linear effect on the flavonoids yield at lowtime levels. This is most likely due to the improvement of flavonoids solubility resulted from the increased mass transfer rate. If the temperature was bigger than a given value (about

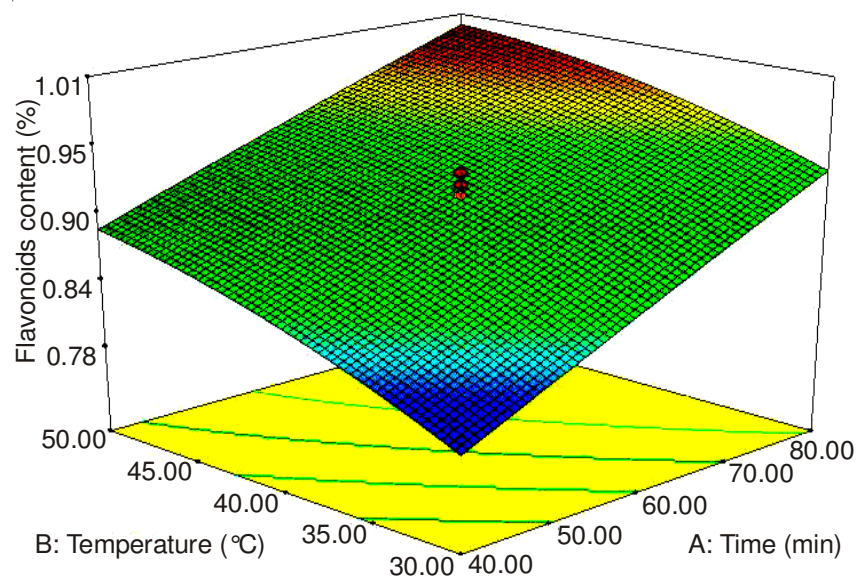

Fig. 1. Response surface (a) and contour plots (b) for the effect of time and temperature on the flavonoids yield 
$50{ }^{\circ} \mathrm{C}$ ), although the seed flavonoids yield been on the rise, the flavonoids were easy to break down and may led to unsafe operation.

Choose a suitable time on ultrasonic-assisted extraction of fenugreek seed flavonoids is very important, because short extraction time led to insufficient extraction and long extraction time that may cause tedious follow-up operation. Fig. 2 showed the effect of extraction time and liquid to solid ratio on the flavonoids. In Fig. 2, we got that time is also a very important factor to extract seed flavonoids from fenugreek by ultrasonicassisted extraction. An increase in flavonoids yield with the increasing time in an early stage of extraction was observed, but the trend was reversed when the time reached a given value (about $80 \mathrm{~min}$ ). At a certain time, the appropriate time and temperature can get the maximum extraction rate.

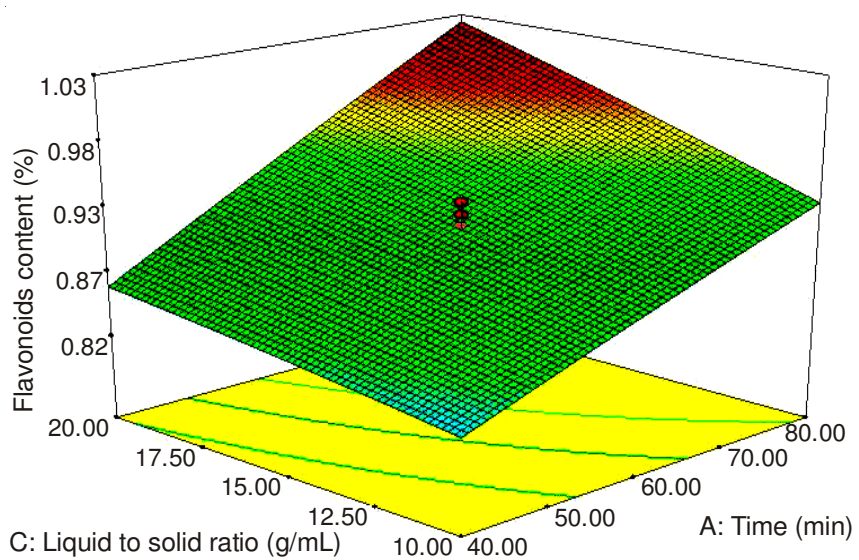

Fig. 2. Response surface (a) and contour plots (b) for the effect of time and liquid to solid ratio on the falvonoids yield

As presented in Fig. 3, it was observed that the yield of flavonoids significantly increased with the increasing liquid to solid ratio. Liquid to solid ratio is another important effect of ultrasonic-assisted extraction flavonoids yield, the influence of this parameter was also significant. From 10 to $20 \mathrm{~g} / \mathrm{mL}$, the seed flavonoids yield straight up over liquid to solid ratio. At the high liquid to solid ratio, the yield is also increasing at a high level, this maybe due to the seed flavonoids was extracted more abundantly with more solvent. Although enlarging the liquid to solid ratio led to increase of the flavonoids yield, but the higher liquid to solid ratio lead to the higher the cost and is not conducive to apply in industrial production. Therefore, we must choose a suitable liquid to solid ratio for ultrasonicassisted extraction of seed flavonoids from fenugreek.

Optimization procedure and verification of optimized models: The optimal conditions obtained by the model were as follows: time of $79.89 \mathrm{~min}$, temperature of $47.60{ }^{\circ} \mathrm{C}$ and liquid to solid ratio of $19.63 \mathrm{~g} / \mathrm{mL}$, the predicated value of flavonoids yield reached maximum value $1.03 \%$. In order to operate conveniently, process parameters were changed slightly but the flavonoids yield was affected little. Lastly, time of $80 \mathrm{~min}$, temperature of $48{ }^{\circ} \mathrm{C}$ and liquid to solid ratio of 20 $\mathrm{g} / \mathrm{mL}$ may be suitable considering factors involved. Verification results revealed that the predicated values from the model were reasonably close to observed values.

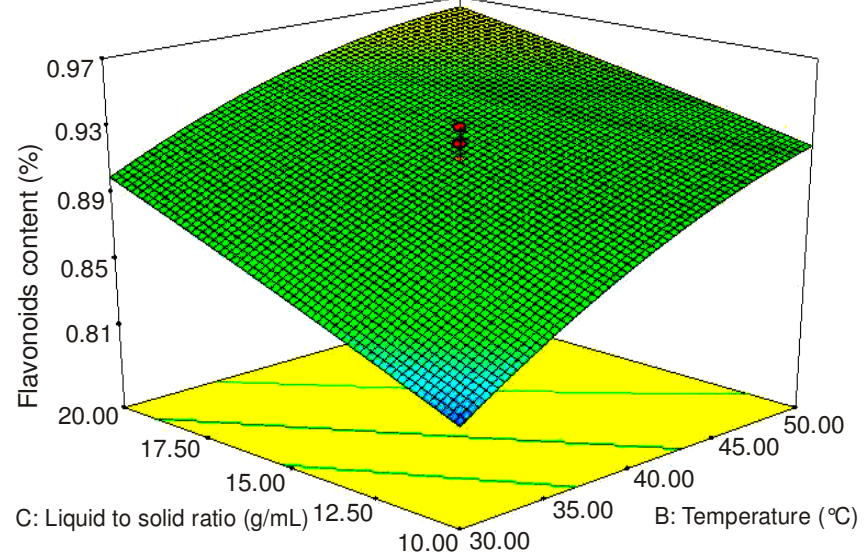

Fig. 3. Response surface (a) and contour plots (b) for the effect of temperature and liquid to solid ratio on the flavonoids yield

\section{Chromatographic separation and mass spectrometry analysis}

HPLC separation: In the present work, a HPLC method for the analysis of the crude sample was established first because a proper detection condition is very important to ensure all flavonoids are detected. The optimization condition was show in "HPLC-DAD analysis", under these conditions mentioned above, the RP-HPLC method provided repeatable and good separation within 50 min for two samples (UAE, HRE).

Flavonoids identification by HPLC-DAD-ESI-MS: By comparing the retention times and UV-visible spectra of the four standards at the same chromatographic conditions, we found the sample got by different extraction process all have the four flavone-c-glycoside. The ionization and fragmentation of the four components agree well with our conclusion. According to the $m / z$ values and two pair isomers that have been recognized from the seeds of fenugreek. As expected, every flavonoids component produced an intense molecular ion peak at $m / z[\mathrm{M}+\mathrm{H}]^{+}$(in ESI-MS spectrum). The selected reaction monitoring, based on the $\mathrm{m} / z[\mathrm{M}+\mathrm{H}]^{+}(449.1) \rightarrow 430.9$ transition for orientin; $[\mathrm{M}+\mathrm{H}]+(449.2) \rightarrow 431.2$ transition for isoorientin; $[\mathrm{M}+\mathrm{H}]^{+}(433.2) \rightarrow 415$ transition for vitexin; [M $+\mathrm{H}^{+}(433) \rightarrow 415.2$ transition for isovitexin. In the ESI-MS/ MS spectra of four flavone-c-glycoside, the fragment ions $[\mathrm{M}+\mathrm{H}-150]^{+},[\mathrm{M}+\mathrm{H}-120]^{+}$and $[\mathrm{M}+\mathrm{H}-96]^{+}$were observed, implying that the glucoside have split up.

Quantitative analysis of fenugreek seed obtained by different extraction process: As showed in Table-3, all the calibration curves exhibit good linear regressions with being all higher than 0.9990 and the ranges of curves are adequate for analyzing the 4 flavonoids. The LOD and LOQ of these four compounds range from 50.94 to $70.31 \mathrm{ng} / \mathrm{mL}$ and 179.63 to $208.85 \mathrm{ng} / \mathrm{mL}$, respectively. Both the LOD and LOQ of these four standards are low enough for detecting traces of the four flavonoids in fenugreek seed.

As shown in Table-4, all the recoveries are in the range of 98.02-100.59\%, suggesting the method is reliable. Based on the regression equation and peak areas of four flavonoids, the content of four flavonoids were be calculated and showed in Table-5. It is found that the four flavonoids in UAE sample are higher than HRE and the result is identical with the total flavonoid result. In the UAE sample, the content of isoorientin is $4.81 \mathrm{mg} / \mathrm{g}$, which is much higher than the other ingredients. 


\begin{tabular}{|c|c|c|c|c|c|c|}
\hline \multicolumn{7}{|c|}{$\begin{array}{l}\text { TABLE-3 } \\
\text { LINEAR REGRESSION EQUATION, CORRELATION COEFFICIENT, LOD AND LOQ FOR } \\
\text { FLAVONOIDS QUANTIFICATION BY HPLC-UV/DAD-MS }\end{array}$} \\
\hline Standard & $\begin{array}{l}\text { Retention time } \\
\text { (min) }\end{array}$ & Regression equation & $\begin{array}{c}\text { Correlation } \\
\text { coefficients (r) }\end{array}$ & Linearity range $(\mu \mathrm{g} / \mathrm{mL})$ & LOD (ng/mL) & LOQ $(\mathrm{ng} / \mathrm{mL})$ \\
\hline Orientin & 22.103 & $y=7.8739 x+0.4113$ & 0.9995 & $6.88-110$ & 60.50 & 200.47 \\
\hline Isoorientin & 23.665 & $y=8.3958 x+0.8730$ & 0.9992 & $7.19-115$ & 70.31 & 214.13 \\
\hline Vitexin & 26.229 & $y=15.2110 x+0.7900$ & 0.9993 & $4.80-77$ & 50.94 & 179.63 \\
\hline Isovitexin & 30.107 & $y=13.6230 x+0.5072$ & 0.9991 & $6.56-105$ & 65.72 & 208.85 \\
\hline
\end{tabular}

\begin{tabular}{|c|c|c|c|c|c|}
\hline \multicolumn{6}{|c|}{$\begin{array}{c}\text { TABLE-4 } \\
\text { RECOVERY }(\%) \text { TEST OF FOUR FLAVONOIDS } \\
\text { FOR THIS METHOD }(\mathrm{n}=3)\end{array}$} \\
\hline Standard & $\begin{array}{l}\text { Original } \\
\text { mean } \\
(\mathrm{mg})\end{array}$ & $\begin{array}{c}\text { Spiked } \\
\text { mean } \\
(\mathrm{mg})\end{array}$ & $\begin{array}{l}\text { Detected } \\
\text { mean } \\
(\mathrm{mg})\end{array}$ & $\begin{array}{c}\text { Recovery } \\
(\%)\end{array}$ & $\begin{array}{l}\text { RSD } \\
(\%)\end{array}$ \\
\hline Orientin & 2.10 & 2.10 & 4.18 & 99.05 & 2.36 \\
\hline Isoorientin & 7.22 & 7.22 & 14.40 & 99.45 & 1.98 \\
\hline Vitexin & 0.93 & 0.93 & 1.85 & 98.92 & 2.21 \\
\hline Isovitexin & 1.70 & 1.70 & 3.41 & 100.59 & 1.68 \\
\hline
\end{tabular}

\begin{tabular}{ccccc}
\multicolumn{5}{c}{ TABLE-5 } \\
CONTENT OF THE FOUR CONSTITUENTS IN \\
FENUGREEK SEED EXTRACTED BY DIFFERENT \\
METHODS (mg/g SEED, $\overline{\mathrm{x}} \pm \mathrm{s})$ \\
\hline Sample & Orientin & Isoorientin & Vitexin & Isovitexin \\
\hline UAE & $1.40 \pm 0.17$ & $4.81 \pm 0.21$ & $0.62 \pm 0.04$ & $1.13 \pm 0.14$ \\
HRE & $0.54 \pm 0.09$ & $4.09 \pm 0.24$ & $0.44 \pm 0.07$ & $0.86 \pm 0.12$ \\
\hline
\end{tabular}

The results also indicated that the UAE method is a simple, convenient, low cost, fast and effective method for sample preparation and pretreatment at the laboratory scale.

\section{Conclusion}

In this paper, flavonoids from fenugreek (Trigonella foenumgraecum L.) seed were extracted by different methods (UAE, HRE). The UAE method is very suit for the seed flavonoids extraction. CCD and RSM were applied for modeling and the prediction of the flavonoids extraction yield. The optimum extraction conditions found by maximizing the dependent variables were time of $80 \mathrm{~min}$, temperature of $48^{\circ} \mathrm{C}$ and liquid to solid ratio of $20 \mathrm{~g} / \mathrm{mL}$, where $1.03 \%$ yield was predicted. Meanwhile, simultaneous determination of four flavonoids was accomplished by a useful and simple HPLC-DAD-ESI-MS/ MS method. In the UAE sample, the content of isoorientin is $4.81 \mathrm{mg} / \mathrm{g}$, which is much higher than the other ingredients. The results also indicated that the UAE method is a simple, low cost, fast and effective method for sample preparation and pretreatment at the laboratory scale. This is the first report of a HPLC/MS method to simultaneous determined the four main flavonoids in fenugreek seed. The assay is reproducible, sensitive and has been fully validated. The results are valuable for further utilizing and development fenugreek as a medicinal and edible plant.

\section{ACKNOWLEDGEMENTS}

Support for this research was provided by the Science and Technology Project of Life Science Excellent Youth of The Chinese Academy of Sciences (KSCX2-EW-Q-23).

\section{REFERENCES}

1. B. Kaufmann, S. Rudaz, S. Cherkaoui, J.L. Veuthey and P. Christen, Phytochem. Anal., 18, 70 (2007).

2. S. Rayyan, T. Fossen and Ø.M. Andersen, J. Agric. Food Chem., 58, 7211 (2010).

3. G.R. Wang, W.Z. Tang, Q.Q. Yao, H. Zhong and Y.J. Liu, J. Nat. Med., 64, 358 (2010).

4. M.A. Pollard, B. Eder, P. Fischer and E.J. Windhab, Carbohydr. Polym., 79, 70 (2010).

5. C.L. Gopu, S.S. Gilda, A.R. Paradkar and K.R. Mahadik, Acta Chromatogr., 20, 709 (2008).

6. M.V. Vijayakumar and M.K. Bhat, Phytother. Res., 22, 500 (2008)

7. P. Sowmya and P. Rajyalakshmi, Plant Foods Hum. Nutr., 53, 359 (1999).

8. Y. Han, S. Nishibe, Y. Noguchi and Z. Jin, Phytochemistry, 58, 577 (2001).

9. M.Y. Shang, S.Q. Cai, J. Han, J. Li, Y.Y. Zhao and J.H. Zheng, China J. Chin. Mater. Med., 23, 614 (1998).

10. J.J. Shan, J.W. Ren, C.M. Wu and Y.M. Zhao, Chin. Pharm. J., 43, 1457 (2008).

11. P. Dixit, S. Ghaskadbi and H. Mohan, L. R.Susan, P. Rajasekaran, Phytother. Res., 19, 977 (2005).

12. G.W. Zhang, L. He and M.M. Hu, Innov. Food Sci. Emerg. Technol., 12, 18 (2011)

13. J.F. Song, D.J. Li, C.Q. Liu and Y. Zhang, Innov. Food Sci. Emerg. Technol., 12, 282 (2011).

14. M.S. Liza, R.A. Rahman and B. Mandana, S. Jinap, A.Rahmat, I.S.M. Zaidul, A. Hamid, Food Bioproducts Process., 88, 319 (2010).

15. D. Bas and I.H. Boyaci, J. Food Eng., 78, 836 (2007).

16. W. Xiao, L. Han and B. Shi, Sep. Sci. Technol., 43, 671 (2008).

17. K.W. Kong, A.R. Ismail, S.T. Tan, K.M. Nagendra Prasad and A. Ismail, Int. J. Food Sci. Technol., 45, 1739 (2010).

18. S.C. Liu, F. Yang, C.H. Zhang, H.W. Ji, P.Z. Hong and C.J. Deng, J. Supercrit. Fluids, 48, 9 (2009). 